\title{
Cutting power prediction model for turning of GFRP composites using response surface methodology
}

\author{
Syed Altaf Hussain ${ }^{1 *}$, V. Pandurangadu ${ }^{2}$, K. Palani Kumar ${ }^{3}$ \\ ${ }^{1 *}$ Department of Mechanical Engineering, RGM College of Engineering \& Technology, Nandyal-51850, INDIA \\ ${ }^{2}$ Department of Mechanical Engineering, JNTUniveristy-Anantapur, Anantapur-, INDIA \\ ${ }^{3}$ Department of Mechanical Engineering, Sri SaiRam Institute of Technology, Chennai-44, INDIA \\ "Corresponding Author: e-mail: s_a_hussain1@rediffmail.com, Tel +91, 9494738100,
}

\begin{abstract}
Glass fiber reinforced plastic (GFRP) composite materials are replacing traditional engineering materials owing to their superior properties. Accordingly, the need for accurate machining of composites has increased enormously. This paper deals with the study of power consumption in machining of GFRP composite tubes of different fiber orientation angle vary from $30^{\circ}$ to $90^{\circ}$. Machining studies were carried out on an all geared lathe using three different cutting tools: namely Carbide (K-20), Cubic Boron Nitride (CBN) and Poly-Crystalline Diamond (PCD). Experiments were conducted based on the established Taguchi's Design of Experiments (DOE) $\mathrm{L}_{25}$ orthogonal array on an all geared lathe. The cutting parameters considered were cutting speed, feed, depth of cut, and work piece (fiber orientation). The data collected was statistically analyzed using Analysis of variance (ANOVA) technique, and a second order mathematical model in terms of cutting parameters was developed using Response surface methodology (RSM). The results indicated that the developed model is suitable for prediction of power consumption in machining of GFRP composites. The experimental results reveals that, lower power consumption was observed at low cutting speed, low feed, moderate depth of cut and low fiber orientation angle. PCD tool performing better compared to the other tools used in this investigation.
\end{abstract}

Keywords: Response surface methodology (RSM), Cutting power, Glass fiber reinforced plastic (GFRP) composites, Analysis of variance (ANOVA).

DOI: http://dx.doi.org/10.4314/ijest.v3i6.13

\section{Introduction}

Glass fiber reinforced plastic (GFRP) composites have become an economic alternative to stainless steel and other materials in highly corrosive industrial applications. They are being extensively used in variety of engineering applications in many different fields such as automobiles, aerospace, oil, household, gas, and process industries. Santhanakrishnan et al (1989) have demonstrated that the GFRP parts made by filament winding techniques sometimes require machining. Even though GFRP parts may be produced by molding processes, they require further machining to facilitate dimensional control for easy assembly and control of surface quality for functional aspects. According to Koing et al. (1985) the machining of fiber reinforced polymers (FRP) is difficult from that of metal in many respects because, the metal behavior is not only inhomogeneous, but also dependent on fiber and matrix properties, and type of weave. According to the literature of Trent (1984), Nagpal (1986) and Kalpakjian (2000) turning operation is one of the most important operation used for machine elements construction in manufacturing industries i.e. aerospace, automotive and shipping. In order to carry out correct calculation in the design of cutting tools, machine tools and fixtures as well as for calculating the rigidity of the machine tool the power consumed in metal cutting is essential.

Turning operation produces three cutting force components as shown in Fig.2 (the main cutting force i.e. thrust force, $\left(\mathrm{F}_{\mathrm{z}}\right)$ which acts in the cutting speed direction, feed force $\left(\mathrm{F}_{\mathrm{x}}\right)$ which acts in the feed rate direction and radial force $\left(\mathrm{F}_{\mathrm{y}}\right)$ acts in the radial direction and which is normal to the cutting speed). Out of three force components the cutting force (main cutting force) 
constitutes about $70 \%$ to $80 \%$ of the total force ' $\mathrm{F}$ ' and is used to calculate the power ' $\mathrm{P}$ ' required to perform the machining operation.

Abhang and Hameedullah (2010) have developed first order and second order power prediction model using response surface methodology (RSM) while machining EN-31 steel and they concluded that, second order model is more accurate model than the first order model.

The machinability of composite materials is influenced by the type of fiber embedded in the composites, and more particularly by the mechanical properties. On the other hand, Rehman et al. (1999) demonstrated that the selection of cutting parameters and the cutting tool are dependent on the type of fiber used in the composites and which is very important in the machining process. Palanikumar (2008) studied the effect of cutting parameters on surface roughness on machining of GFRP composites by polycrystalline diamond (PCD) tool by developing a second order model for predicting the surface roughness. Palanikumar et al. (2006) have developed a procedure to asses and optimize the chosen factors to attain minimum surface roughness by incorporating response table and response graph, normal probability plot, interaction graphs, and analysis of variance (ANOVA) technique. Tekeyama and Lijma (1988) studied the surface roughness on machining of GFRP composites, according to them, higher cutting speed produce more damage on the machined surface. This is attributed to higher cutting temperature, which results in local softening of work material. They also studied the machinability of FRP composites using the ultra sonic machining technique. Adam khan et al. (2011) has carried out machining studies on GFRP composites using two alumina cutting tools. The machining process was performed at different cutting speeds at constant feed rate and depth of cut. The performance of the alumina cutting tool was evaluated by measuring the flank wear and surface roughness of the machined GFRP composite material. As seen from the literature, only limited work has been carried out on prediction of cutting power in machining of Glass fiber Reinforced Plastics (GFRP) composites. Thus, this present work aims at investigating the effect of cutting speed, feed, depth of cut and fiber orientation angle on power consumption in machining of GFRP composites, during the turning with three different cutting tool inserts viz., carbide (K-20), CBN and PCD has been analyzed by developing the RSM based second order mathematical model.

The equation for the cutting power is: $\mathrm{P}=\mathrm{F}_{\mathrm{z}} * \mathrm{~V}$ Watts

Where $\mathrm{P}$ is the power in watt, $\mathrm{V}$ is the cutting speed in $\mathrm{m} / \mathrm{min}$ and $\mathrm{F}_{\mathrm{z}}$ is the main cutting force in $\mathrm{N}$ (Metal Cutting And Cutting tool Design, MIR Publishers 1976, Moscow). The power is dissipated mainly in the shear zone (due to the energy required to shear the material) and on the rake face of the tool (due to tool-chip interface friction). The sharpness of the tool tip also influences forces and power. Because it rubs against the machined surface and makes the deformation zone ahead of the tool larger, the worn out tools require higher forces and power.

\section{Materials and methods}

The work material used for the present investigation was glass fiber reinforced plastic (GFRP) tubes. The inner diameter of the pipe was $30 \mathrm{~mm}$, the outer diameter was $60 \mathrm{~mm}$ and length $500 \mathrm{~mm}$ respectively. The tubes used in the study were manufactured by filament winding process. The orientation of the fibers on the works piece was set during the manufacture of tubes. The roving were wound at an angle in the range of $30^{\circ} \sim 90^{\circ}$. The specification of fiber and resin used in this work are given in Table 1.

Table 1. Specifications of fiber and resin

\begin{tabular}{ll}
\hline Fiber: E-glass - R099 1200 P556 & Resin: Epoxy \\
\hline Manufacturer: Saint Gobain vetrotex India Ltd. & Manufacturer: CIBA GEIGY \\
R099- Multi filament Roving & Product: ARALDITE MY 740 IN 110KG Q2 \\
1200-Linear Density, Tex & Hardner: HT 972 \\
P556- Sizing reference for vetrotex & \\
\hline
\end{tabular}

\subsection{Response Surface Methodology}

Response surface methodology (RSM) is a collection of mathematical and statistical techniques that are useful for modeling and analysis of problems in which a response of interest is influenced by several variables and the objective is to optimize this response, Montgomery (1991). Palanikumar and Karthikeyan (2007) have developed a second order mathematical model using $\mathrm{RSM}$ to predict surface roughness on machining of $\mathrm{Al} / \mathrm{Sic}$ particulate composite material. In the present work, second order RSM based mathematical model of cutting power $(\mathrm{P})$ have been developed in terms of in terms of four process parameters, namely, cutting speed (v), feed (f), depth of cut (d) and fiber orientation angle $(\Phi)$.

In many engineering fields, there is a relationship between an output variable of interest ' $y$ ' and a set of controllable variables $\left\{\mathrm{x}_{1}, \mathrm{x}_{2} \ldots \ldots \mathrm{x}_{\mathrm{n}}\right\}$. in some systems, the nature of relationship between $\mathrm{y}$ and $\mathrm{x}$ values might be known. Then, a model can be written in the form

$$
Y=f\left(x_{1}, x_{2}, \ldots--\cdot-x_{n}\right)+\varepsilon
$$


Where $\varepsilon$ represents noise or error observed in the response ' $\mathrm{Y}$ '

If we denote the expected response be $\mathrm{E}(\mathrm{Y})=\mathrm{f}\left(\mathrm{x}_{1}, \mathrm{x}_{2}, \ldots-\mathrm{xn}_{\mathrm{n}}\right)=\widehat{Y}$ is called response surface. The first step is to find suitable approximation for the true functional relationship between y and set of independent variables employed usually a second order model is used in RSM.

$\widehat{Y}=\beta_{0}+\sum_{i=1}^{k} \beta_{i} X_{i}+\sum_{i=1}^{k} \beta_{i i} X_{i}^{2}+\sum_{i} \sum_{j} \beta_{i j} X_{j}+\varepsilon$

The $\beta$ coefficients, used in the above model can be calculated by means of using least square method. The second-order model is normally used when the response function is not known or nonlinear.

\section{Experimental details}

The experiments are conducted as per the Taguchi's orthogonal array $\mathrm{L}_{25}$ design of experiments. The four cutting parameters selected for the present investigation is cutting speed (v)m/min, feed (f) $\mathrm{mm} / \mathrm{rev}$, depth of cut (d)mm and work piece (fiber orientation ' $\Phi$ ') in degrees. Since the considered factors are multi-level variables and their outcome effects are not linearly related. The machining parameter used and their levels chosen are given in Table 2. All the GFRP tubes are turned in a BHARAT all-geared lathe of model NAGMATI-175 with a maximum speed of $1200 \mathrm{rpm}$ and power of $2.25 \mathrm{KW}$. The ISO specification of the toll holder used for the turning operation is a WIDAX tool holder PC LNR $2020 \mathrm{~K} 12$ and the tool insert used for the study are carbide K-20, (CNMA 120408), CBN (CNMA 120408T MB825) and PCD (CNMA 120408) (Diamond 80 shape tool with hole and without chip breaker).

Table 2. Cutting parameters, their notations and their limits

\begin{tabular}{lccccccc}
\hline Process parameters (with units) & \multicolumn{8}{c}{ Levels } \\
& Notation & Variable & -2 & -1 & 0 & +1 & +2 \\
\hline Cutting speed, m/min & $\mathrm{V}$ & $\mathrm{x}_{1}$ & 40 & 60 & 95 & 145 & 225 \\
Feed, mm/rev & $\mathrm{f}$ & $\mathrm{x}_{2}$ & 0.048 & 0.096 & 0.143 & 0.191 & 0.238 \\
Depth of cut, mm & $\mathrm{d}$ & $\mathrm{x}_{3}$ & 0.25 & 0.5 & 0.75 & 1.0 & 1.25 \\
Fiber orientation & $\Phi$ & $\mathrm{x}_{4}$ & 30 & 45 & 60 & 75 & 90 \\
angle, deg & & & & & & & \\
\hline
\end{tabular}

In machining, the cutting force is measured using a KISTLER quartz 3-component dynamometer type 9257B. The dynamometer measures the active cutting force regardless of its application point. The dynamometer is connected to a 3-channel charge amplifier type 5807A through a connecting cable type 1687B5, this in turn is connected to the PC by a 37-pin cable from the A/D board. The dynamometer is calibrated for the cutting force in the range from 0 to $1000 \mathrm{~N}$. To get accuracy in measuring the cutting force, it is measured three times and average of cutting forces has been taken for analysis. The schematic layout of the experimental setup is shown in Fig 1. A special attachment has been prepared for fixing the GFRP composite tube in the tailstock of the lathe. Fig. 2 shows the details of the force measurement.

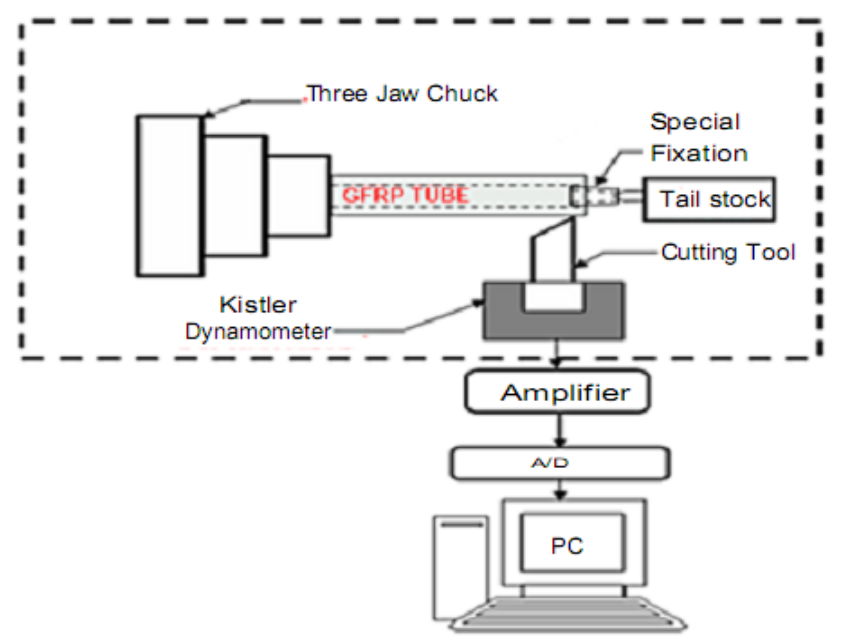

Figure 1: Schematic layout of the experimental setup 


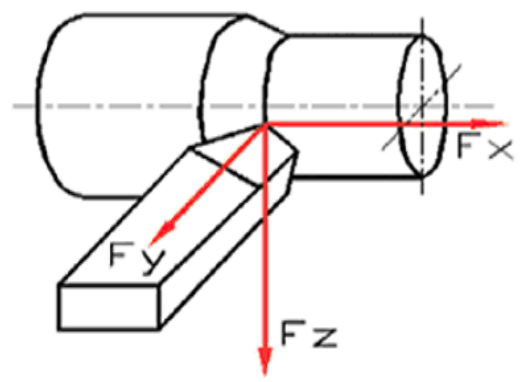

Figure 2: Details of the force measurement

\subsection{Mathematical model for cutting power}

In the present work, the second-order quadratic RSM based mathematical models were developed for cutting power (P), for the three cutting tools namely Carbide (K-20) and CBN tool and PCD are presented in Table 3.

Table 3 Model summary for cutting power

\begin{tabular}{|c|c|c|c|}
\hline Type of Tool & Model Expression & $\mathrm{R}^{2}$ & $\operatorname{Adj} R^{2}$ \\
\hline Carbide (K-20) & $\begin{array}{l}58+5.93 \mathrm{~V}+322 \mathrm{f}+168 \mathrm{~d}-5.07 \Phi- \\
0.00746 \mathrm{~V}^{*} \mathrm{~V}+147 \mathrm{f}^{*} \mathrm{f}-171 \mathrm{~d}^{*} \mathrm{~d}- \\
0.0150 \Phi^{*} \Phi+7.33 \mathrm{~V}^{*} \mathrm{f}-2.47 \mathrm{v}^{*} \mathrm{~d}+ \\
0.0482 \mathrm{~V}^{*} \Phi+242 \mathrm{f}^{*} \mathrm{~d}-7.87 \mathrm{f}^{*} \Phi+5.93 \\
\mathrm{~d}^{*} \Phi .\end{array}$ & 0.996 & 0.9904 \\
\hline CBN & $\begin{array}{l}209+2.11 \mathrm{~V}-1369 \mathrm{f}+159 \mathrm{~d}-3.37 \Phi+ \\
0.00403 \mathrm{~V}^{*} \mathrm{~V}+3279 \mathrm{f}^{*} \mathrm{f}-47 \mathrm{~d}^{*} \mathrm{~d}+ \\
0.0291 \Phi^{*} \Phi+8.72 \mathrm{~V}^{*} \mathrm{f}+0.08 \mathrm{~V}^{*} \mathrm{~d}+ \\
0.0252 \mathrm{~V}^{*} \Phi+128 \mathrm{f}^{*} \mathrm{~d}+6.03 \mathrm{f}^{*} \Phi-1.76 \\
\mathrm{~d}^{*} \Phi .\end{array}$ & 0.9975 & 0.9940 \\
\hline PCD & $\begin{array}{l}122-2.44 \mathrm{~V}-2054 \mathrm{f}+129 \mathrm{~d}+5.60 \Phi+ \\
0.00990 \mathrm{~V}^{*} \mathrm{~V}+5941 \mathrm{f}^{*} \mathrm{f}+205 \mathrm{~d}^{*} \mathrm{~d}- \\
0.0435 \Phi^{*} \Phi+25.7 \mathrm{~V} * \mathrm{f}-1.22 \mathrm{~V}^{*} \mathrm{~d}+ \\
0.0204 \mathrm{~V}^{*} \Phi-1682 \mathrm{f}^{*} \mathrm{~d}-2.77 \mathrm{f}^{*} \Phi+1.01 \\
\mathrm{~d}^{*} \Phi .\end{array}$ & 0.995 & 0.9881 \\
\hline
\end{tabular}

Where $V$ is cutting speed $(\mathrm{m} / \mathrm{min}), \mathrm{f}$ is feed $(\mathrm{mm} / \mathrm{rev}), \mathrm{d}$ is depth of cut $(\mathrm{mm})$ and $\Phi$ is fiber orientation angle in deg.

The statistical testing of the developed mathematical models was done by Fisher's statistical test for the analysis of variance (ANOVA). As per ANOVA, if the calculated value of F-ratio of the regression model is more than the standard tabulated value of the F-table for a given confidence interval, then the model is adequate within the confidence limit. The results of ANOVA at $95 \%$ confidence interval are presented in Table 4 and it is found that the developed mathematical models are highly significant at $95 \%$ confidence interval as F-ratio of all three models is greater than $2.83\left(\right.$ F-table $\left._{(14,10,0.05)}\right)$.

The coefficient of determination $\left(\mathrm{R}^{2}\right)$ is also determined to test the goodness-of fit of the mathematical model, which provides a measure of variability in the observed values of response and can be explained by the controlled process parameters and their interactions. The $\mathrm{R}^{2}$ values of the developed models are given in Table 3, which clearly indicate the excellent correlation between the experimental and the predicted values of the responses. Adding a variable to the model will always increase $\mathrm{R}^{2}$, regardless of whether the additional variable is statistically significant or not. In this discussion including unnecessary terms, $\mathrm{R}^{2}$ can be artificially high. Unlike $\mathrm{R}^{2}$, adjusted $\mathrm{R}^{2}$ will often decrease, when unnecessary terms are added to the model.

Adjusted $\mathrm{R}^{2}$ will be taken into consideration, when the number of independent variables included in the model in the model. Hence, adjusted $\mathrm{R}^{2}$ is more appropriate than $\mathrm{R}^{2}$ for comparing models with different number of independent variables. When $\mathrm{R}^{2}$ and adjusted $\mathrm{R}^{2}$ differ dramatically, there is a good chance that non-significant terms have been included in the model.

From the models, it was revealed that the co-efficient of determination $\left(\mathrm{R}^{2}\right)$ is more than $95 \%$ in all the cases, which shows high correlation exists between the model and experimental values. 
Table 4. ANOVA results for cutting power models of three different tools viz: Carbide (K-20), CBN and PCD.

\begin{tabular}{|l|c|c|c|c|c|c|c|}
\hline & \multicolumn{2}{|c|}{ Sum of squares } & \multicolumn{2}{c|}{ Degree of freedom } & & \\
\hline Response & Regression & Residual & Regression & Residual & Regression & Residual & F-ratio \\
\hline $\begin{array}{l}\text { Tool: Carbide } \\
\text { (K-20) }\end{array}$ & & & & & & & \\
\hline $\begin{array}{l}\text { Cutting } \\
\text { power }\end{array}$ & 4018525 & 16137 & 14 & 10 & 287037 & 1614 & 177.87 \\
\hline Tool : CBN & & & & & & & \\
\hline Cutting power & 4168474 & 10394.9 & 14 & 10 & 297748 & 1029.49 & 317.16 \\
\hline Tool: PCD & & & & & & & \\
\hline Cutting power & 125355.4 & 3600.11 & 14 & 10 & 8933.99 & 366.011 & 24.46 \\
\hline
\end{tabular}

\section{Results and discussions}

In the present work a comprehensive analysis is carried out to study the effect of different cutting tool material on cutting power with variation of cutting speed, feed, and depth of cut for different fiber orientation angle GFRP composites. For analyzing the influence of machining parameters on power consumption in machining of different fiber orientation angle $\left(30^{0}-90^{\circ}\right)$ GFRP composites, the cutting powers is calculated at different machining conditions and are plotted as shown in figures3-5. The graphs are drawn with the help of response surface model observed. In these graphs only one variable is in variation in nature by keeping other variables constant at the middle level.

\subsection{Analysis of cutting power}

Cutting power is the product of main cutting force and the cutting velocity and is a better criterion for design and selection of any machine tools. Power consumption may be used for monitoring the tool conditions. The variation of observed cutting power at different machining parameters in machining of GFRP composites of different fiber orientation angle by three different cutting tool inserts is presented in figures 3-5. The graphs are drawn with the help of response surface model observed. In these graphs only one variable is in variation in nature by keeping other variables constant at the middle level.

\subsubsection{Effect of cutting tool materials on cutting power with varying cutting speed}

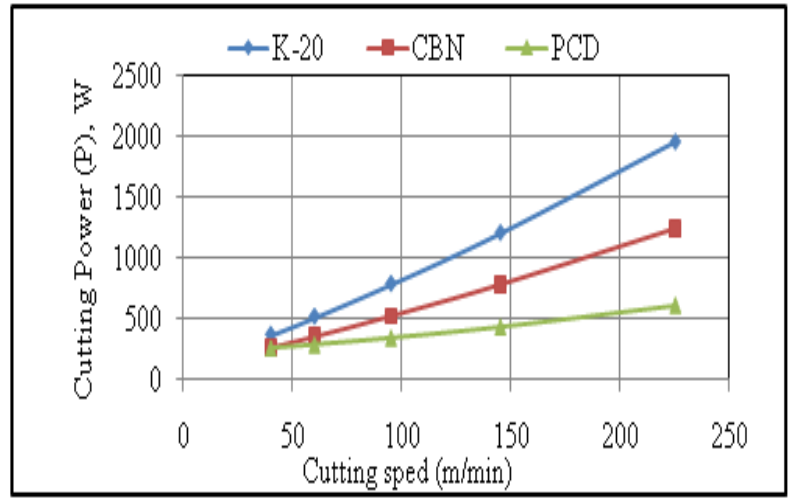

(a) Effect of cutting tool material on cutting Power with varying cutting speed on $30^{\circ}$ Fiber orientation angle GFRP composite.

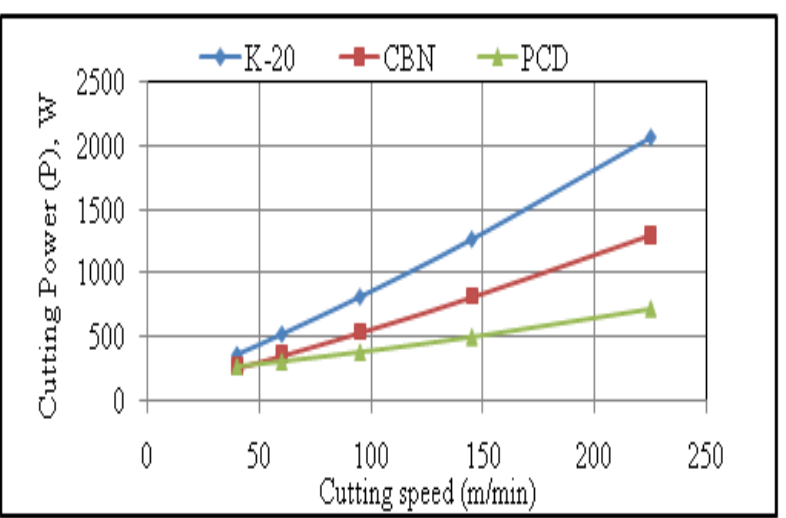

(b) Effect of cutting tool material on cutting power with varying cutting speed on $45^{0}$ fiber orientation GFRP composite. 


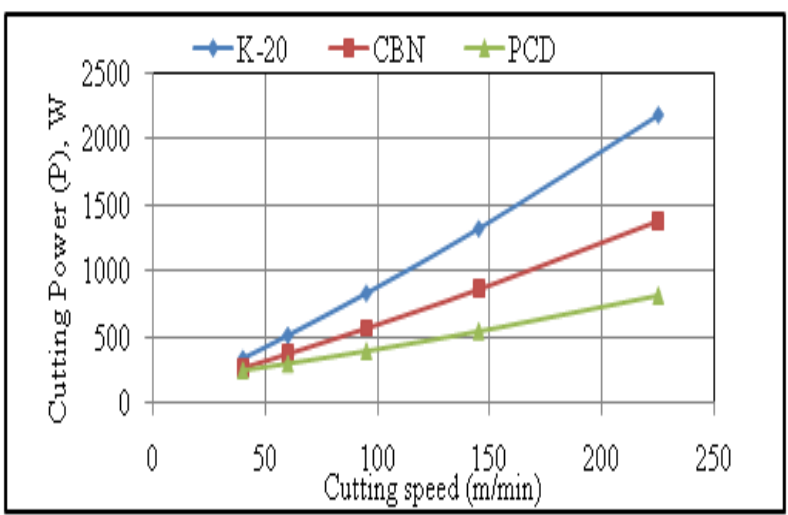

(c) Effect of cutting tool material on cutting Power with varying cutting speed on $60^{\circ}$ fiber orientation angle GFRP composite.



(d) Effect of cutting tool material on cutting power with varying cutting speed on $75^{\circ}$ fiber orientation GFRP composite.

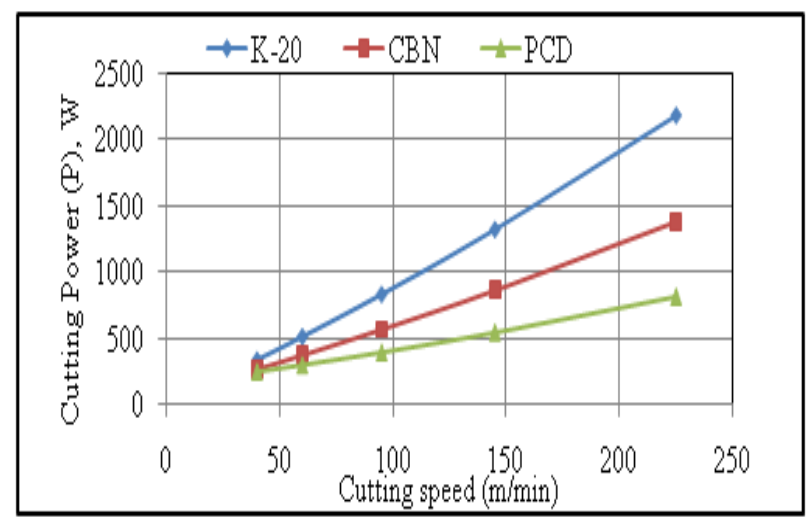

(e) Effect of cutting tool materail on cutting power

With varying cutting speed on $90^{\circ}$ fiber orientation

Angle GFRP composite.

Figure 3 (a-e): Effect of cutting tool materials with varying cutting speed on cutting power

Figure 3 (a-e) illustrates the effect of cutting tool material on cutting power with varying cutting speed in GFRP composite materials of different fiber orientation angle ranges from $30^{\circ}$ to $90^{\circ}$ with three cutting tool inserts. From the graphs it is observed that cutting power is directly proportional to the cutting speed, this is because, the cutting power is the product of cutting force and cutting speed (Arshinov and Alekseev 1976) as that cutting speed increases, the cutting power also increases for all three different types of cutting tool inserts used in the present investigation. It can be seen from the graphs that lower cutting power range from (263.72W-616.08W) was noticed for $30^{\circ}$ fiber orientation GFRP composite material machined with PCD cutting tool insert. For larger fiber orientation angle GFRP composite materials the cutting power is higher for all the cutting tools used in the present investigation. Figure 3 (a-e) reveals that PCD tool insert performs better and yields lower cutting power (P) for all the GFRP composite materials used in the present investigation and this followed by CBN tool insert. Carbide (K-20) was not satisfactory compared to the other tools used in this investigation. 


\subsubsection{Effect of cutting tool materials on cutting power with varying feed}

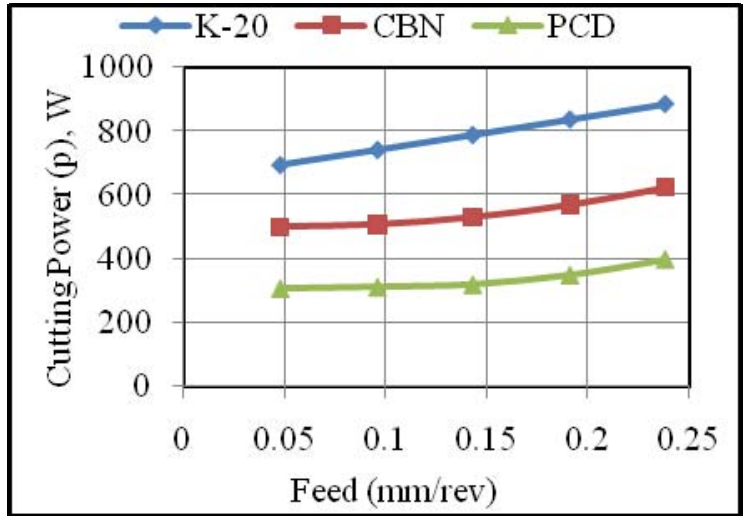

(a) Effect of cutting tool material on cutting power With varying feed on $30^{\circ}$ fiber orientation angle GFRP composite.

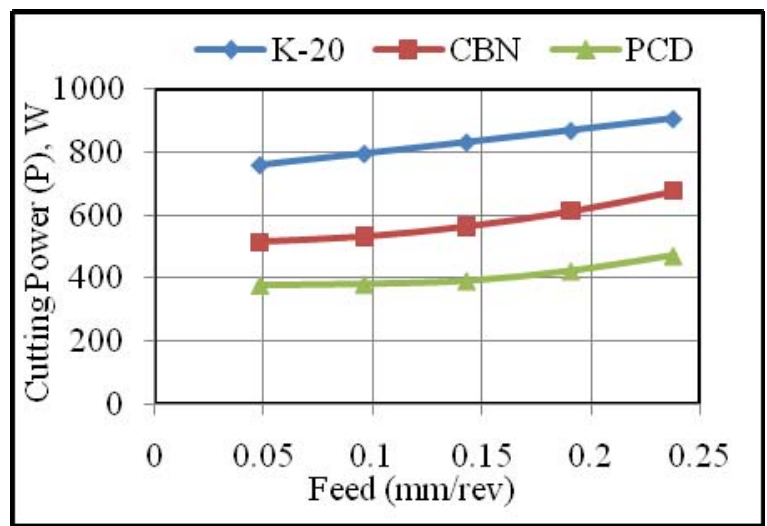

(c) Effect of cutting tool material on cutting power With varying feed on $60^{\circ}$ fiber orientation angle GFRP composite.

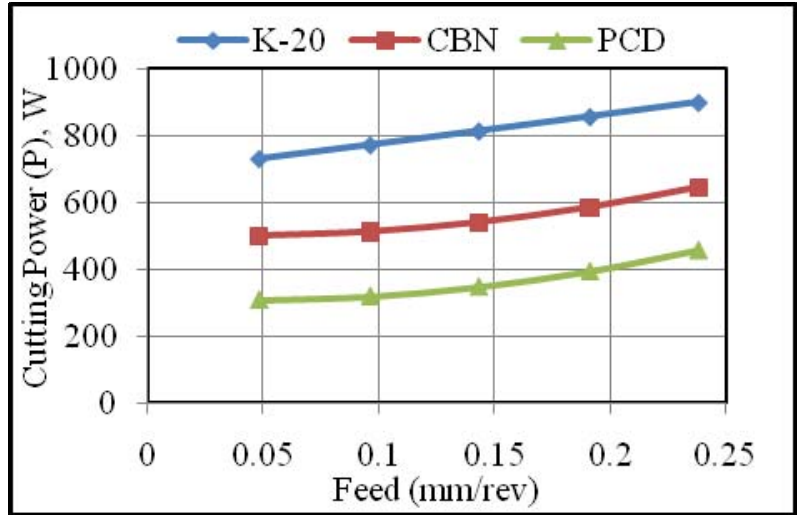

(b) Effect of cutting tool material on cutting power with varying feed on $45^{\circ}$ fiber orientation angle GFRP composite.

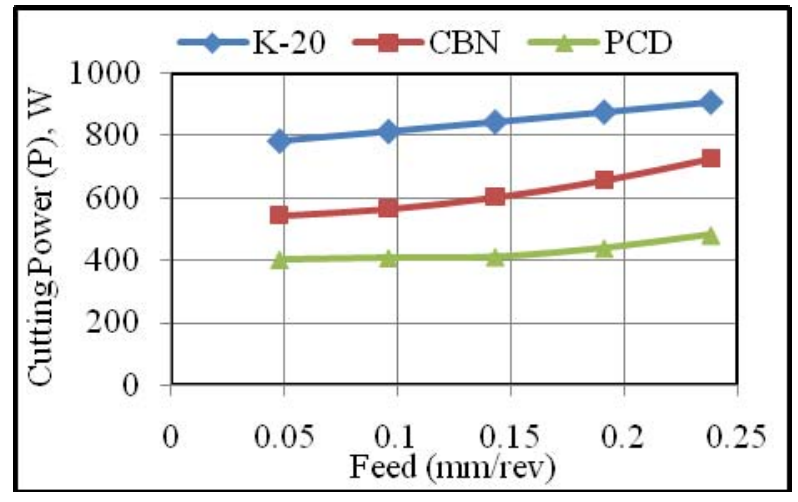

(d) Effect of cutting tool material on cutting power with varying feed on $75^{\circ}$ fiber orientation angle GFRP composite.

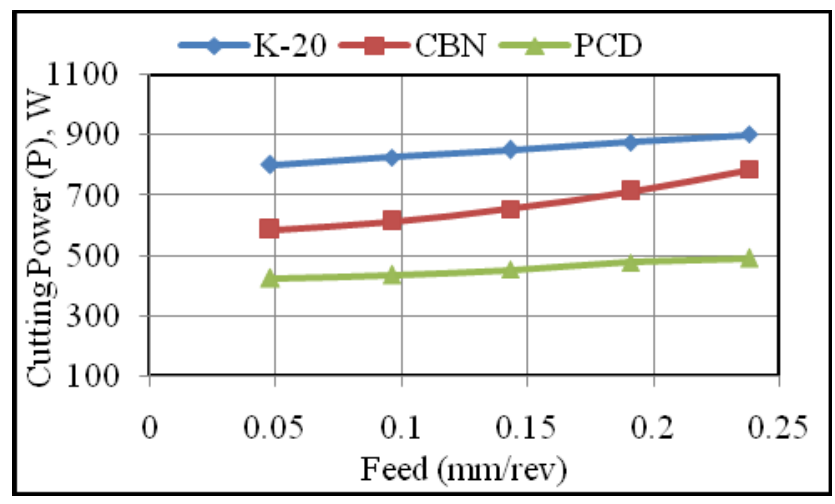

(e) Effect of cutting tool material on cutting power With varying feed on $90^{\circ}$ fiber orientation angle GFRP composite.

Figure 4 (a-e): Effect of cutting tool materials on cutting power with varying feed on GFRP composites. 
Figure 4 (a-e) illustrates the effect of effect of cutting tool material on cutting power with varying feed on GFRP composite materials of different fiber orientation angles ranges from $30^{\circ}$ to $90^{\circ}$. These graphs are drawn with the help of response surface model by keeping one variable in variation and keeping the other variable constant at the middle level. From the graphs it is asserted that, cutting power gradually increases with increase of feed rate for all GFRP composite materials of different fiber orientation angles vary from $30^{\circ}-90^{\circ}$ with three different cutting tool inserts used in the present investigation. The cutting power is minimum at lower values of feed rate. It can be seen from the graphs that, lower values of cutting power range from $(307.01 \mathrm{~W}-$ $398.49 \mathrm{~W}$ ) was noticed for $30^{\circ}$ fiber orientation angle GFRP composite with PCD cutting tool insert compared to other fiber orientation angle GFRP composite material considered in the present investigation. Figure 4(a-e) reveals that PCD tool insert performs better and yields lower cutting power for all the GFRP composite materials used in the present investigation and this followed by CBN tool insert. Because of high uniform hardness and wear rate of cutting edge is slower than that of carbide tools. Carbide (K-20) was not satisfactory compared to the other tools used in this investigation.

\subsubsection{Effect of cutting tool materials on cutting power with varying depth of cut}

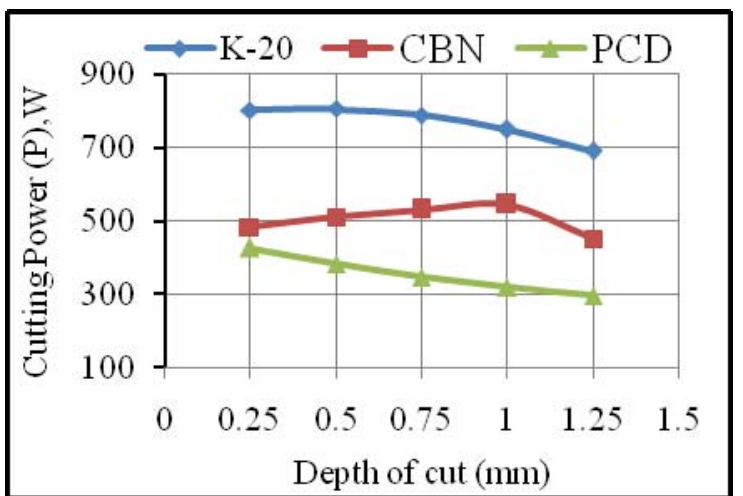

(a) Effect of cutting tool material on cutting power With varying depth of cut on $30^{\circ}$ fiber orientation angle GFRP composite.

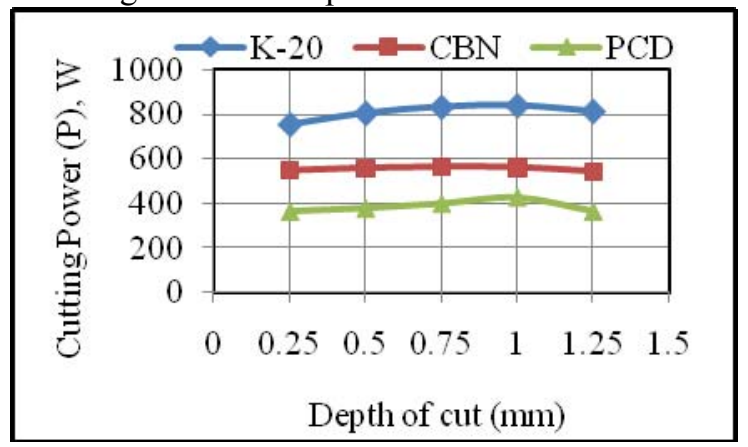

(c) Effect of cutting tool material on cutting power With varying depth of cut on $60^{\circ}$ fiber orientation angle GFRP composite.

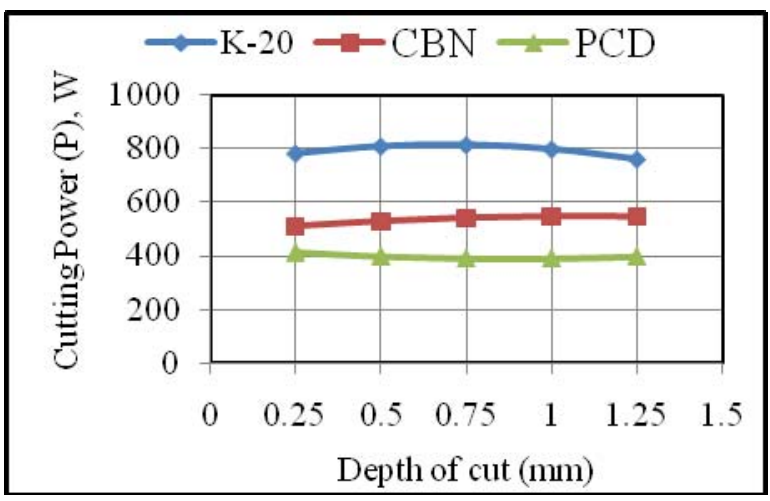

(b) Effect of cutting tool material on cutting power with varying depth of cut on $45^{\circ}$ fiber orietnation angle GFRP composite.

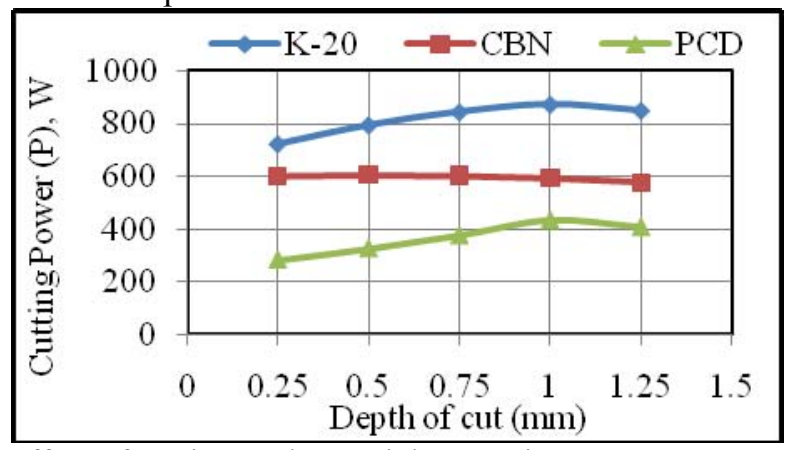

(d) Effect of cutting tool material on cutting power with varying depth of cut on $75^{\circ}$ fiber orietnation angle GFRP composite.

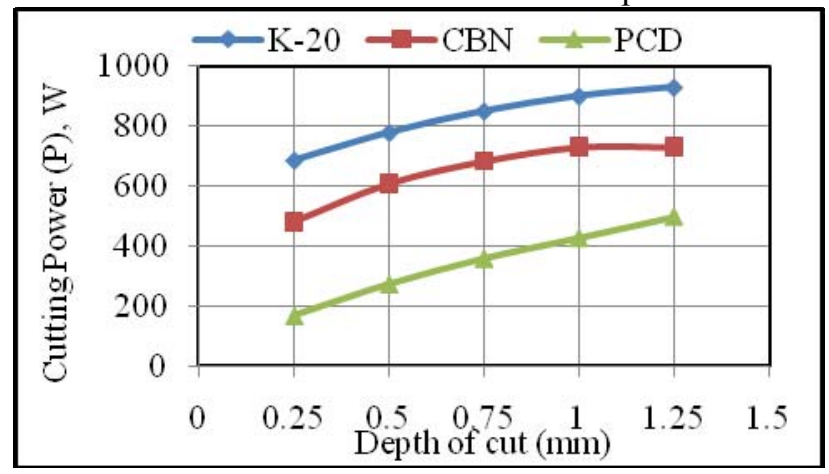

(e) Effect of cutting tool material on cutting power With varying depth of cut on $90^{\circ}$ fiber orientation angle GFRP composite.

Fig: 5 (a-e): Effect of cutting tool materials on cutting power with varying depth of cut 
For analyzing influence of cutting tool material the on cutting power (P) in machining of GFRP composite materials of different fiber orientation angle vary from $\left(30^{\circ}-90^{\circ}\right)$ with varying depth of cut, the cutting power is calculated for each fiber orientation angle GFRP composite material with the help of response surface model by keeping the one variable in variation in nature by keeping the other variable constant at the middle level. Figure 5 (a-e) illustrates the effect of cutting tool material on cutting power with varying depth of cut on GFRP composite materials of different fiber orientation angle ranges from $30^{\circ}$ to $90^{\circ}$ with three cutting tool inserts. From the graphs it is observed that cutting power gradually increases with increasing the depth of cut up to a value of $1.0 \mathrm{~mm}$ there after slightly decreased for all three different types of cutting tool inserts used in the present investigation. It can be seen from the graphs that lower cutting power range from $(390.39 \mathrm{~W}-411.71 \mathrm{~W})$ was noticed for $30^{\circ}$ fiber orientation GFRP composite material with PCD cutting tool insert. For larger fiber orientation angle GFRP composite materials the cutting power is higher with all the cutting tools used in the present investigation.

Figure 5(a-e), strongly support the conclusion that the performance of PCD tool is superior to the other cutting tool inserts used in this investigation. PCD cutting tools are designed to machine tough, abrasive non ferrous and non-metallic materials, they are very hard and maintain a keen cutting edge for long production runs. The sharp cutting edge shear the chip clearly and reduce the friction force of the chip sliding over rake surface of the tool by virtue of this closer dimensional tolerance is obtained on GFRP composites.

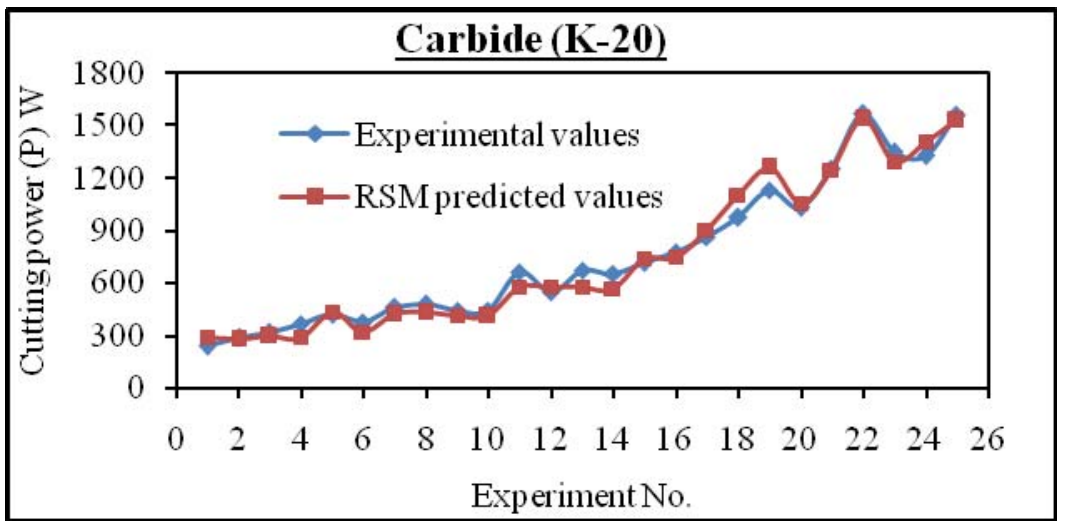

(a) Cutting power: Comparison between experimental values and RSM Predicted values for Carbide-(K20) insert.

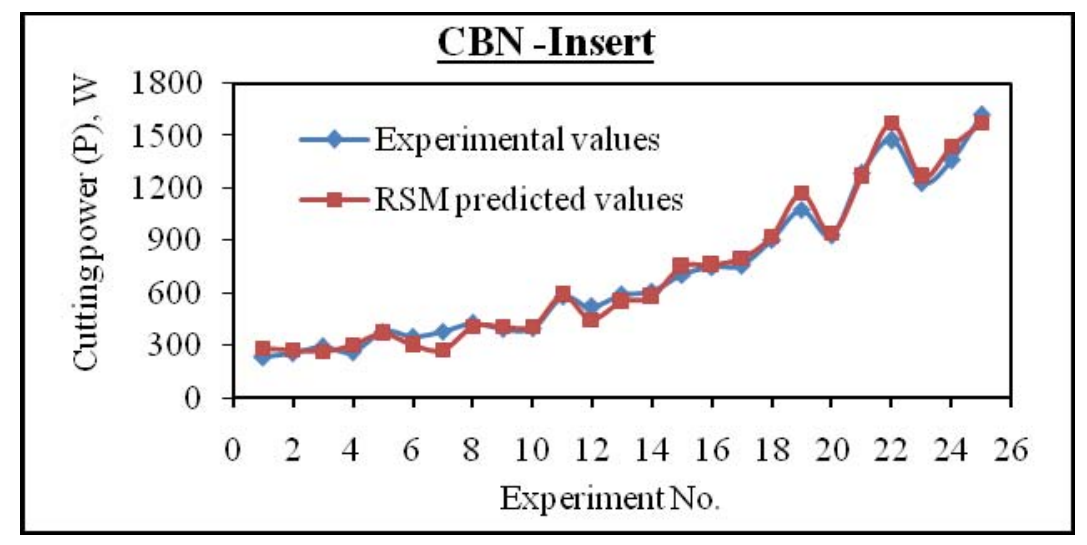

(b) Cutting power: Comparison between experimental values and RSM Predicted values for CBN insert. 


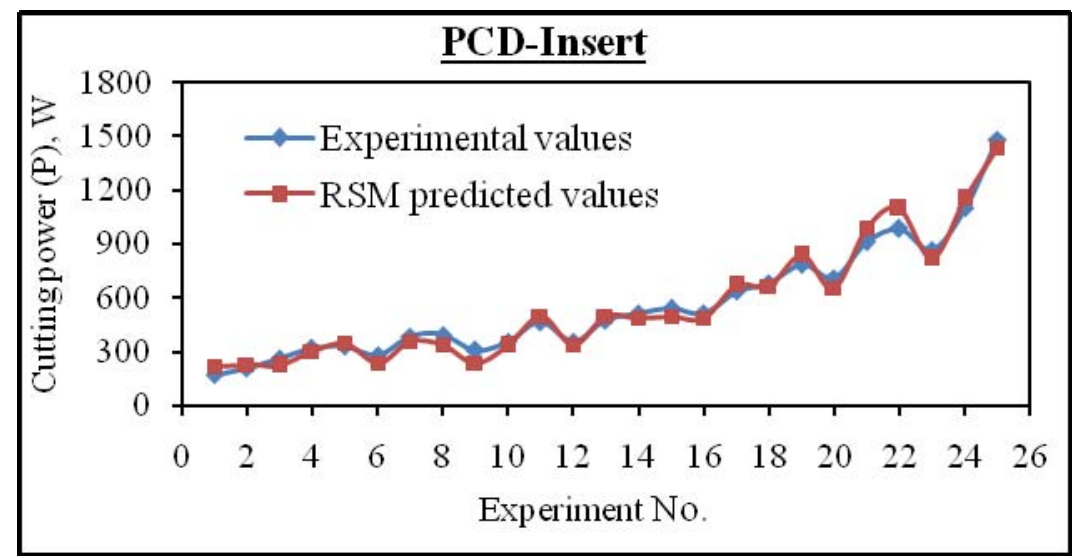

(c) Cutting power: Comparison between experimental values and RSM Predicted values for PCD insert.

Figure 6(a-c): Cutting power - Comparison between the experimental values and RSM predicted values

Figure 6 (a-c) shows the comparison between the experimental results and RSM predicted values for the cutting power for the three different cutting tools. From the graphs it is asserted that a close relationship exits between the experimental results and RSM predicted values. Also the results confirm that RSM model can be effectively used to predict the cutting power for machining of GFRP composites with $95 \%$ confidence interval. Using such model one could remarkably save time and cost.

\section{Conclusion}

Experiments were conducted on a lathe with three different cutting tool inserts viz., Carbide (K-20), CBN and PCD on GFRP composite specimens of different fiber orientation angle $30^{\circ}-90^{\circ}$. The data, cutting power were collected under different cutting conditions for various combinations of cutting speed, feed and depth of cut using Taguchi's $\mathrm{L}_{25}$ orthogonal array.. Based on the experimental results, the following conclusions are drawn within the range of parameters selected.

- Response surface methodology is found to be successful for modeling and analysis of cutting power in machining of GFRP composite materials with respect to various combinations of design variables (cutting speed, feed, depth of cut and fiber orientation angle).

- The developed second order response surface model can be used to calculate the cutting power in machining of GFRP composite material at different cutting conditions within the chosen range with $95 \%$ confidence intervals. Using such models, one can obtain remarkable saving in time and cost.

- Lower power consumption was observed at lower cutting speed, low feed, high depth of cut and lower fiber orientation angle GFRP composites, while machining with Poly-Crystalline Diamond (PCD) cutting tool.

- Higher cutting powers are required for larger fiber orientation angle GFRP composite materials.

- Carbide (K-20) tool gave high power consumptions. Hence, it is not at all desirable to use this tool for machining of GFRP composites.

\section{References}

Adam khan.M and A. Senthil kumar., 2011. Machinability of glass fiber reinforced plastic (GFRP) composites using aluminabased ceramic cutting tools International Journal of Manufacturing Process, Vol. 13, No.1, pp. 67-73.

Abhang L.B and Hameedullah M., 2010. Power Prediction Model for Turning EN-31 Steel Using Response Surface Methodology Journal of Engineering Science and Teechnology Review, Vol. 3, No.1, pp. 116-122.

Arshinov.V and Alekseev.G., 1976, Metal Cutting Theory And Cutting tool Design, MIR Publishers, Moscow

König.W, Ch. Wulf, P. Grab and H. Willerscheid., 1985. A theory of machining of fiber reinforced plastics. CIRP AnnalsManufacturing Technology, Vol. 34, pp. 537-548.

Kalpakjian S., 2000. Manufacturing Engineering and Technology, 4th Edition, Illinois Institute of technology; pp. 545-548.

Montgomery DC., 1991, Design and analysis of experiments. John Wiley and sons, NewYork,

Nagpal G. R., 1986, Machine Tool Engineering. Khanna Publishers, New Delhi, pp. 68-71

Palani kunar.K, Karuna moothy. L and Kathikeyan. R .,2006. Assessment of factors influencing surface roughness on machining of Glass fiber reinforced polymer Composites, Materials \& Design, Vol. 27, No.10, pp. 863-871. 
Palanikumar K. and Karthikeyan R., 2007. Assessment of factors influencing surface roughness on the machining of $\mathrm{Al} / \mathrm{Sic}$ particulate composites, Material and Design, Vol. 28, pp. 1584-1591.

Palanikumar, K,. 2008. Application of Taguchi and response surface methodology for surface roughness in machining glass fiber reinforced plastics by PCD Tooling, International Journal of Materials Processing Technology, Vol. 36, No. (1-2), pp. 19-27.

Rahman M, Ramakrishnan S, Prakesh S, Tan DCG., 1999. Machinability study of carbon fiber reinforced composites, Journal of. Material Process Technology, Vol. 89-90, pp. 292-297.

Santhanakrishnan G, Krishnamurthy R, Malhotra SK., 1989. High-speed steel tool wear studies in machining of glass-fiber reinforced plastics, Wear, Vol. 132 , No.2 pp. 327-336.

Trent E. M., 1984, Metal cutting, 2nd edition, Butterworth's \& Co. London, UK, limited, ISBN 0-408- pp.34-38.

Tekeyama. H and Lijima. N., 1998. Machinability of Glass fiber Reinforced plastics and application of ultrasonic machining, Annals of the CIRP, Vol.37, No.1, pp. 93-96.

\section{Biographical notes}

Mr.Syed Altaf Hussain*, is an Associate Professor in the Department of Mechanical Engineering, RGM College of Engineering \& Technology, Nandyal518501,(A.P), India. He was graduated in Mechanical Engineering from Regional Engineering College, Waangal, A.P and Post graduated in the specialization of Machine Design from JNTU College of Engineering, Kakinada. At present he is pursuing Ph.D from JNT University, Anantapur, A.P, India. He has more than 13 years of experience in teaching. His current area of research includes Machining of composite materials, Finite Element methods, Optimization, Simulation and Modeling.

Dr. V. Pandurangadu is a professor in the Department of Mechanical Engineering, JNT University-Anantapur, Anantapur-515002, Andhra Pradesh, India. He has more than 25 years of experience in teaching and research. His current area of research includes Alternative fuels for an I.C Engines, Combustion of fuels, Machining of composite materials.

Dr. K. Palanikumar is a principal, Sri Sairam Institute of Technology, Chennai-44, India. He obtained Ph.D degree in Mechanical Engineering from Anna university, Chennai, India. He has more than 17 years of experience in teaching and research. His current area of research includes Machining of composite materials, Modern manufacturing, Optimization, Simulation and Modeling.

Received August 2011

Accepted October 2011

Final acceptance in revised form November 2011 